Faculdade de Ciências Econômicas UFRGS
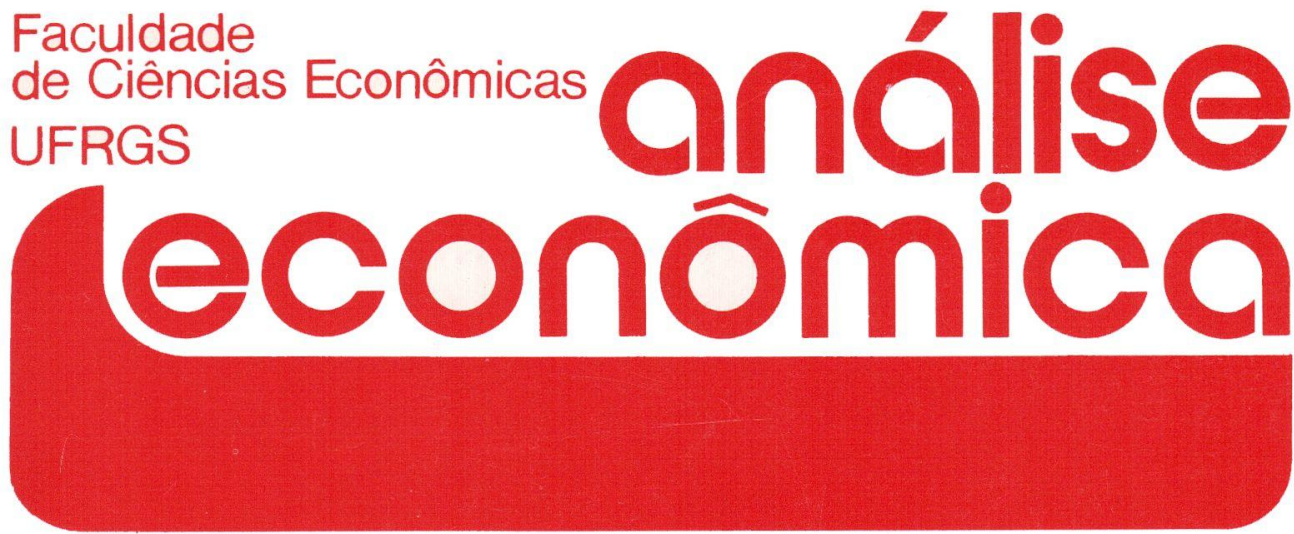

- INDEXAÇĀo SALARIAL: UMA ABORDAGEM MACROECONÓMICA Jo Anna Grav

- AJUSTE NO EMPREGO E PRODUTIVIDADE NA DECADA DE OITENTA

Carlos Antônio Luque José Paulo Zeeteno Chahad

- O CONSUMIDOR KEYNESIANO Marcelo Córtes Neri

- HETEROGENEIDADE DO TRABALHO E TAXA DE LUCRO EM MARX

Francisco Cribari Neto

- ECONOMIAS DE ESCALA: UMA REVISĀO Jesiel de Marco Gomes

- Concentraçấo bancária no BRASIL

Marcelo Resende

- NOYOS RUMOS PARA O SETOR ELETRICO NO BRASIL

Adriano Pires Rodrigues

Eduardo da Cunha Vianna

- OFERTA E DEMANDA DE FRANGO DE CORTE NO BRASIL

Narciso Gonçalves de Castro et alii

- ANÁLISE ECONÔMICA DA IRRIGAÇÃo DO MILHO

Lúcia M Schirmer

Juvir Luiz Mattuella

- REFLORESTAMENTO NO BRASIL. Carlos José Caetano Bacha

- ESCOLHA DE TECNOLOGIA EM ESTRUTURA DE PRINCIPAL AGENTE Kyle D. Kauffma:

- A QUESTÁo DEMOGRÁfica e A PRAXEOLOGIA

Anton Karl Biedermann et alii
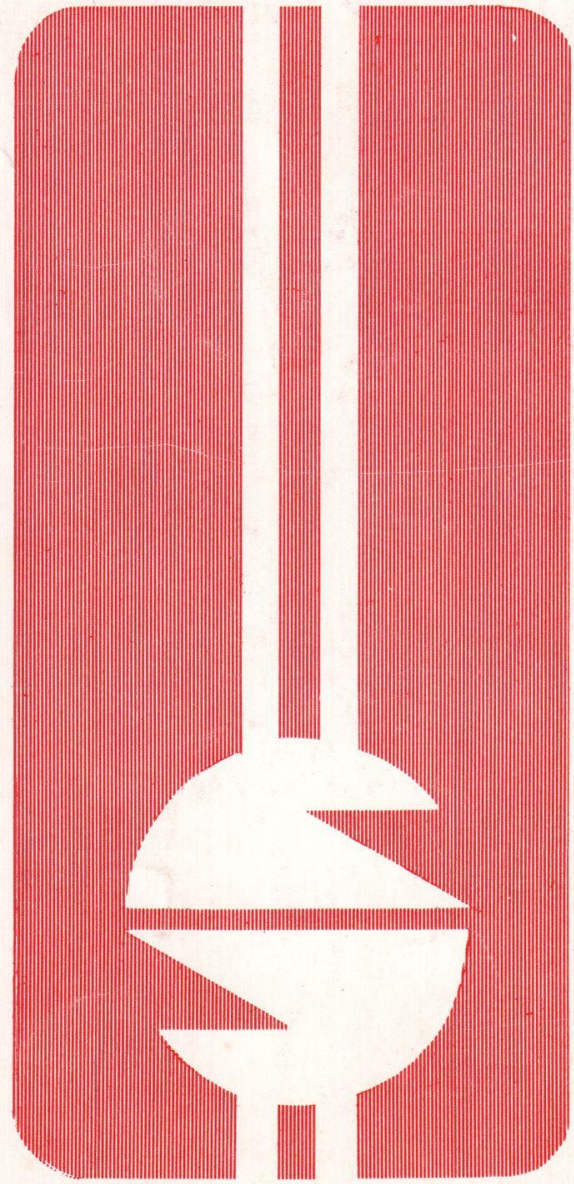
UNIVERSIDADE FEDERAL DO RIO GRANDE DO SUL

Reitor: Prof. Tuiskon Dick

FACULDADE DE CIÉNCIAS ECONÔMICAS

Diretora: Prof ${ }^{\text {a }}$ Yeda Rorato Crusius.

CENTRO DE ESTUDOS E PESQUISAS ECONÔMICAS

Diretor: Reinaldo Ignacio Adams

DEPARTAMENTO DE CIÉNCIAS ECONÔMICAS

Chefe: Prof. Fernando Ferrari Filho

CURSO DE POS-GRADUAÇÄO EM ECONOMIA

Coordenador: Prof. Nali de Jesus de Souza

CURSO DE PÓS-GRADUAÇĀO EM ECONOMIA RURAL

Coordenador: Prof. Atos Freitas Grawunder

CONSELHO EDITORIAL: Achyles Barcelos da Costa, Aray Miguel Feldens, Atos Freitas Grawunder, Carlos Augusto Crusius, Ernani Hickmann, João Rogério Sanson, Juvir Luiz Mattuella, Maria Imilda da Costa e Silva, Nali de Jesus de Souza, Nuno Renan Lopes de Figueiredo Pinto, Otilia Beatriz Kroeff Carrion, Otto Guilherme Konzen, Paulo Alexandre Spohr, Pedro Cezar Dutra Fonseca, Reinaldo Ignacio Adams, Roberto Camps Moraes, Valter José Stülp, Yeda Rorato Crusius, David Garlow (Wharton Econometrics Forecasts Association, E.U.A.), Edgar Augusto Lanzer (UFSC), Eleutério F.S. Prado (USF), Fernando Holanda Barbosa (FGV/RJ), Gustavo Franco (PUC/RJ), Joaquim Pinto de Andrade (UnB), Juan H. Moldau (USP), Werner Baer (Univ. de Illinois, E.U.A.).

COMISSĀO EDITORIAL: Atos Freitas Grawunder, Pedro Cezar Dutra Fonseca, Reinaldo Ignacio Adams e Roberto Camps Moraes.

EDITOR: Nali de Jesus de Souza

SECRETARIA: Maria Ivone de Mello (normalização), Vanete Ricacheski (revisão de textos).

FUNDADOR: Prof. Antônio Carlos Santos Rosa

Os materiais publicados na revista Análise Econômica são de exclusiva responsabilidade dos autores. É permitida a reprodução total ou parcial dos trabalhos, desde que seja citada a fonte.

Aceita-se permuta com revistas congêneres. Aceitam-se, também, livros para divulgação, elaboração de resenhas ou recenșões.

Toda correspondência, material para publicação, assinaturas e - permutas devem ser dirigidos ao seguinte destinatário:

\section{PROF. NALI DE JESUS DE SOUZA}

Revista Análise Econômica

Av. João Pessoa, 52

CEP 90040-000 - PORTO ALEGRE (RS), BRASIL

Telefones: (051) 228-1633 - 224-6024 ramais 3440 e 3348

Fax: (051) 225-1067 


\title{
NOVOS RUMOS PARA O SETOR ELÉTRICO NO BRASIL
}

\author{
Adriano Pires Rodrigues* \\ Eduardo da Cunha Vianna**
}

\section{SINOPSE}

Existe hoje o consenso de que o setor eletrico se apresenta com graves problemas económico-financeiros, que pб̄em em risco sua expansăo futura. Neste momento tambên de crise fiscal do "Estado do Bem-Estar", ganham força as teses favoraveis à privatizaç̆̊̆ de empresas do setor produtivo estatal, af inclufdas as empresas do setor elétrico. Particularmente, tem tido bastante ressonancia as teses que atribuem à ineficiéncia do Estado-empresário a causa da crise.

Diante desta constatação, o objetivo deste trabalho $\in \mathbf{o}$ de averiguar que fatos realmente contribufram para o completo domfnio das empresas públicas no setor elétrico, assim como examinar as razס́es do esgotamento da capacidade financeira do setor a partir do final dos anos setenta e, finalmente, discutir sobre a viabilidade de sua privatizaçăo.

Dentro do debate que envolve a situação atual do setor elétrico brasileiro há um consenso: o setor elétrico encontra-se mergulhado numa crise sem precedentes na sua história. Quando se observa o atual quadro institucional do setor elétrico brasileiro onde cerca de $90 \%$ da capacidade de geração de energia elétrica pertence a concessionárias públicas, a conclusão é a de que a crise do setor expressa-se na incapacidade das empresas públicas continuarem comandando a expansão, como o fazem desde meados dos anos sessenta. Neste contexto, diante não só da crise do setor como também da própria crise fiscal do Estado, a privatização tem sido posta crescentemente como uma solução. Contudo, dentro do grupo daqueles que defendem a privaiização do setor elétrico e de outros segmentos do Setor Produtivo Estatal, há uma clara divisão de posicionamento, já que não há unanimidade no que se refere ao argumento-base da necessidade da privatização.

De um lado, estão aqueles que vêm na privatização a única solução possível para que se ponha fim na ineficiência que assola o sistema eco-

* Professor e Coordenador do PPE/COPPE/UFRJ.

** Mestre em Planejamento Energético, COPPEJUFRJ.

ANÅLISE ECONÔMICA

\begin{tabular}{|l|l|l|l|}
\hline ANO 10 & NNo 17 & MARÇO/92 & F.109-115 \\
\hline
\end{tabular}


nómico, difundida pela inépcia do Estado-empresário. Esta tem sido a bandeira do discurso neoliberal em prol da privatização em larga escala, e af, nesse caso, exemplos como o da Inglaterra e do Chile são sempre citados com experiências bem-sucedidas.

Este argumento, segundo os defensores do intervencionismo estatal, estaria tomado de profundo maniquefsmo. Primeiramente, porque o setor privado e visto como a encarnação da eficiência, ao passo que o Estado-empresário é o seu oposto - a fonte de ineficiência. Em segundo lugar, não se considera que a empresa pública apresenta uma ambigüidade, ou seja: ela ao mesmo tempo tem uma face empresarial e uma face governo. Assim, a empresa pública, quando está atendendo aos interesses ditos "públicos", expressos nas diretrizes de política macroeconômica, pode estar agindo em desacordo com os seus interesses empresariais, que revelam sua face micro ou privada. Desta forma, as empresas públicas que conseguiram desenvolver "válvulas de escape" à ingerências governamentais, como contençāo de tarifas públicas, puderam manter-se como empresas viáveis.

Entretanto, a contraposição às idéias neoliberais não deve ser entendida, absolutamente, como uma postura simétrica; a existência da propriedade pública não implica, necessariamente, a melhor opção para a sociedade. Mais importante que a propriedade pública ou privada do agente produtivo $\epsilon$ a politica publica, a saber, aquela que ocasionará na apropriação pública dos seus resultados.

Na outra margem do rio, mas sem seguir as águas da corrente neoliberal, estão aqueles que reconhecem que tanto a regulação, quanto a intervenção direta do Estado, consubstanciada na atuação das empresas públicas, foram indispensáveis ao crescimento da economia brasileira. Contudo, entenden que o padrão de acumulação baseado na intervenção estatal apresenta-se esgotado em suas possibilidades. Portanto, deverá ocorrer o que normalmente acontece nas recessóes ćrclicas do Capitalismo: o recuo do Estado em prol da iniciativa privada, para que a recuperação se processe. $E$ isto só ucorrerá na contingência de uma reforma institucional que permita a privatização de áreas da economia dominadas pela atuação do Estado e que se apresentam estranguladas, impossibilitadas de investir em expansão da capacidade. Mas, este recuo do Estado não se dará em definitivo (mesmo porque o próprio processo de privatização não pode prescindir da participação do Estado), pois durante a fase de retomada do crescimento será fundamental uma nova onda de intervenção do Estado, que terá, entretanto, caráter diverso do que hoje presenciamos.

Dentre os que partilham deste pensamento, destaca-se o nome do Ignacio Rangel, que, de longa data, defende a privatização dos serviços de utilidade pública como a via para a retomada do crescimento. Isto 
porque, verifica-se em nosso sistema econômico a polarização típica das crises ć́clicas do Capitalismo, ou seja, convivermos hoje com um pólo de serviços de utilidade pública - , e outro pólo superdimensionado, acumulando recursos - o setor privado. Constatado este fato, RANGEL. vê a privatização como a única alternativa para carrear os recursos ociosos para o setor que se apresenta estrangulado e, assim, gerar uma série de encadeamentos que nos poriam novamente na rota do crescimento econômico.

É preciso deixar claro que RANGEL não corrobora as idéias de que a empresa privada é naturalmente mais eficiente que a empresa pública: (este $€$ um) "equfvoco no qual estão incorrendo muitos "privatólogos' - perdoem-me o neologismo - visto como nossa história recente está pejada de exemplos de brilhantes êxitos da gestão pública, em campos em que a iniciativa privada falhou redondamente, ou pelos quais, nem sequer se aventurou" (RANGEL, 1988).

Rangel destaca que a concessão de serviços de utiliüade pública a empresas públicas possibilitou a grande concentração de recursos, através do comprometimento de recursos fiscais futuros, e que sem este acúmulo de capitais, seria impossivel os grandes projetos como as usinas de Itaipu e Tucurur. Contudo, este quadro institucional apresenta-se hoje saturado e sua modificação é condição sine qua non para a expansão do setor de infra-estrutura.

Desta forma, a concessão da exploração dos serviços públicos, a empresas públicas é vista como uma contradição em si, na medida em que o Estado $\varepsilon$, ao mesmo tempo, poder concedente e concessionário. Por este motivo, quando as empresas públicas recorrem às operações de crédito, o uso da garantia hipotecária (ou seja, o comprometimento dos ativos do concessionário como garantia ne ato da concessão) não se realiza, pois, sendo o Estado o detentor dos bens dos concessionários, não faz sentido aceitar a hipoteca dos bens das empresas públicas. Nesse momento, a expansão dos serviços públicos depende fundamentalmente da utilização de recursos fiscais coletados e da sua antecipação, através de créditos obtidos com o aval do Tesouro Nacional. Como este sistema de captação de recursos apresenta-se saturado, o resultado tem sido um endividamento desmesurado do Estado e das suas unidades produtivas. $\mathrm{Na}$ realidade, a transferência dos recursos do setor privado às áreas de produção dos serviços públicos já existe, visto que grande parte da capitalização das empresas públicas se dá via endividamento, avalizado pelo Tesouro, junto à iniciativa privada. Porém, a divida das empresas do setor de serviços públicos cresce sem resultar em aumento de capital. Todo este quadro gera um avanço ilimitado das taxas de juros, que são cobradas em prazos cada vez menores, na razão direta da desconfiança do credor em relação ao devedor: o Estado. 
Dessa maneira, a crise estrutural da impossibilidade de expansão da capacidade de oferta de serviços públicos só será resolvida com a criação de um novo quadro institucional auto-sustentável e confiável. Isto implica, necessariamente, a privatização dos serviços públicos; pois, só assim, a capitalização destes setores se dará com base numa garantia real - a garantia hipotecária do ativo do concessionário. Portanto, a antiga garantia de recursos fiscais futuros, avalizada pelo Tesouro, hoje sem credibilidade, dará lugar à garantia hipotecária, também avalizada pelo Estado, com a diferença de que esta será uma garantia real. Conseqüentemente, o Estado passará a assumir a dupla função Poder Concedente e Credor Hipotecário, em vez da sua presente posição de devedor insolvente, uma vez que o Estado é o único tomador possível dos títulos emitidos pelos concessionários privados, garantidos hipotecariamente, pois somente ele poderá absorver os ativos destas empresas, em caso de inadimplência. Assim, as empresas poderão obter créditos públicos em bases bem melhores do que as que são agora impost $\cong$ 1o Estado.

Nesse momento estará nascendo no País o Capitalismo Financeiro e a privatização $\varepsilon$ parte deste nascedouro, assim como o são as novas atribuições do Estado. Uma delas seria a de atuar na faixa de intermediaçãc, ao ser avalista dos papéis emitidos pelo setor privado, atuando como "banco, (. . .), no sentido lato do termo. Com efeito, quem se interessará pela concessão de um serviço público, se isto não the abrir a porta de capitais de terceiros". Caberá também ao Estado facilitar a canalização de grande parte da capacidade ociosa existente no interior das multinacionais. Isto se dará através de sua atuação no comércio exterior, pois só ele pode assumir compromissos de lorigo prazo, tanto em relação às importaçôes, quanto em relação às exportações.

Estabelecido, o Capitalismo Financeiro terá função não só de reunir condiçũes para o acesso dos setores estrangulados a novos capitais, corno também para o acessu à tecnoiogia novísima, o que nos levará à retomada do crescimento econômico. No caso brasileiro, a superação da crise cf́clica parece mais fácil do que para os países desenvolvidos, pois o que se apresenta como nova tecnologia nos países do primeiro mindo, em virtude de sua ampla superioridade, relativamente à tecnologia disponivel no Brasil, representa, para nós, a novtssima tecnologia. Mas a ela só teremos acesso após a realização de reforma institucionol que substitua o sistema de concessão dos serviços públicos a empresas privadas nacionais, vale dizer, financiadas em moeda nacional, pouco importando se o investidor $\epsilon$, à luz do Direito Internacional Privado, nacional ou não nacional.

A situação particular do setor elétrico é perfeitamente pertinente com a nossa análise anterior. A história mostra que toda expansão da produção dos serviços de utilidade pública brasileiros se deu com base 
em um novo padrão institucional. Assim aconteceu a partir da década de 1930 quando a expansão foi comandada pelas empresas estrangeiras, destacando-se os grupos Light e AMFORP. Tal predomínio se estendeu por aproximadamente três décadas, até que a progressiva desaceleração da ampliação da capacidade produtiva do setor levou o Estado a intervir no setor elétrico, gerando um novo quadro institucional, onde o setor privado passou a ser minoritário.

O debate travado hoje sobre novos rumos do setor elétrico, confronta duas posições: de um lado, os que propugnam pela reestruturação econômico-financeira do setor elétrico como a condição básica para seu crescimento sustentado. De outro lado, aqueles que defendem que a recuperaçāo somente ocorrerá com uma ampla revisão do quadro institucional vigente, que passará pela discussão dos papéis exercidos pelo poder central, pela Eletrobrás, pelas empresas estaduais, enfim, por todos os atores que preenchem o atual cenário do setor elétrico.

Contudo, $\epsilon$ importante chamar a atenção que somente um processo amplo de privatização não será condição suficiente para a sấda da crise devido a alguns aspectos que precisam ser discutisbs sem preconceitos e corporativismos. Os mais importantes são:o comprometimento de capitais que a privatização das concessionárias públicas exigira; a questão tarifária; o endividamento externo do setor elétrico; a oposição nacionalista; a característica do empresariado brasileiro.

Uma primeira colocação consiste em argüir sobre a capacidade financeira do setor privado para adquirir as grandes empresas públicas do setor elétrico. Diante da magnitude dos ativos das empresas geradoras do setor, como CHESF, CEMIG, CESP, que as colocam entre as dez maiores do pars, a alienação de algumas destas empresas implicaria um brutal acúmulo previo de poupança no setor privado. Mesmo admitindo a hipótese da existência de capital suficiente para a aquisição de empresas deste porte, torna-se muito remota a possibilidade de que persistam recursos disponfveis para fazer fac a as investimentos de expansão.

Possivelmente, diante de um aparente consenso a respeito deste cenário, muitas são as propostas em torno das melhores alternativas para a atração de capitais privados para o setor elétrico. A abertura do capital das empresas do setor, com o estabelecimento do domínio acionário minimo por parte do setor público; o incentivo à autoprodução e à co-geração de energia; a construção de grandes centrais hidrelétricas através de consórcio com o setor privado; a privatização da gestāo empresarial: a antecipação do pagamento dos serviços, à semelhança do que ocorre no setor de telecomunicações, são algumas das diversas sugestōes que estão sendo postas em debate.

Um outro entrave que se apresenta é a questão tarifária, que pode ser desmembrada na defasagem real do valor das tarifas e na sua equali- 
zação em todo o pafs. Certamente, uma participação mais significativa dos investimentos privados no setor elétrico será acompanhada de uma pressão pelo estabelecimento de tarifas diferenciadas e pela recuperação real do valor das mesmas. Em suma, uma pressão pela desregulação parcial do Estado.

Outro aspecto a ser mencionado é o de que qualquer processo de privatização dentro do setor elétrico deverá ser precedido de um equacionamento das responsabilidades relativas ao endividamento externo do setor, na medida em que a Eletrobrás foi o grande agente captador e, conseqüente, repassador dos recursos externos. Do contrário, estar-se-á privatizando apenas o ativo das empresas públicas, permanecendo parte significativa do passivo em posse do Estado.

Um obstáculo que gostarfamos de colocar, consiste nas prováveis pressóes nacionalistas que adviriam da proposta de uma ampla privatização das empresas do setor elétrico. Mesmo sabendo que a legislação vigente impede a constituição da maioria de capital externo na composição das estatais privatizadas, a participação mais significativa do capital externo na composição acionária das concessionárias públiæas poderá gerar um movimento de oposição. Considerando que, mesmo na Grã-Bretanha, que detém a maior experiência privatizante, exatamente a privatização do setor elétrico tem sido considerada uma das mais diffceis de todo o processo de privatização, pode-se extrapolar para a situação do Brasil (onde a experiência privatizante, até aqui, praticamente se ateve à devolução ao setor privado das empresas absorvidas pelo Estado) e antever os problemas decorrentes de pressões contrárias à venda de empresas do setor elétrico, que normalmente contará com o capital externo entre os compradores.

Não se pode relevar, outrossim, que a existência recente mostra o nacionalismo como um dos poucos temas que têm promovido a convergência de propósitos entre setores da esquerda e da direita parlamentar. Além do que, segmentos da sociedade organizada têm-se mostrado com considerável poder de pressão, quando são tratadas questōes deste nfvel. A importância deste tópico amplia-se ao lembrarmos que a privatização é um programa que, teoricamente, se pretende definitivo. Portanto, $c$ consenso político a respeito da sua necessidade talvez seja, ao lado da questão tarifária, um dos pilares do processo de privatização.

Por fim, a característica do capitalista brasileiro, avesso ao risco, trabalhando sempre segundo a sinalização do governo, mostra-se, para nós, como mais um empecilho. Nossa interpretação, porem, é de que o setor privado, muito menos por ser "schumpeteriano", mas por ter conhecimento da realidade que se apresenta, está disposto a dar sua contribuição para a solução dos grandes problemas do setor elétrico.

Não resta dúvida que garantir a expansão da capacidade de geração 
de energia elétrica até o inf́cio do próximo século será um grande desafio. Tanto o setor público quanto o setor privado, sozinho, são incapazes de sustentar este projeto. Portanto, o norte da discussão, presente e futura, deverá estar centrada nas medidas necessárias para que seja viabilizada a ação conjunta dos setores público e privado. No entanto, um passo inicial poderia ser a liberação das empresas públicas (federais e estaduais) para atuarem enquanto empresas que procurem alcançar metas definitivas e que, portanto, possam ser cobradas pelas suas respectivas performances, adquirindo assim direitos, mas também deveres perante a sociedade brasileira.

\title{
BIBLIOGRAFIA
}

CASTRO, A. B. Amargo Despertar. Rumos do Desenvolvimento, anu 12, no 68, 1987, p. 4-10.

RANGEL, I. M. A Logica da Privatização. Folha de São Paulo, 20 agosto 1985.

- O Papel dos Serviços de Utilidade Pública, Seminário Crise Urbana e Privatização dos Serviços Páblicos, Rio de Janeiro, CCJE/UFRJ, 1987.

1990.

- A Privatização e a Lei. Folha de São Paulo, 22 agosto 1988.

. O Quarto Ciclo de Kondratiev. Revista de Economia Política, vol. 10, no 4,

\begin{abstract}
The fact that the electricity sector in Brazil is now facing serious economic and finantial constraints, which in fact jeopardise its prospective expansion, is a consensus. This, alongside with the sharp downfall in revenues that the "Social Welfare State" is undergoing has clearly favoured the position of those who are for the privatisation of the whole state-owned productive sector, including the companies of the electricity area. In particular, the idea that the present crisis is due to the failure of the state as entrepreneur has gainel significant grounds.

In view of this reality, the chief goal of the present piece of academic work is to ascertain the factors that, over the years, have contributed to the absolute rule of the government-owned enterprises over the entire electricity sector, in Brazil.

An inevitable by-product of such approach is what we intended to be a thorough research into the causes of the utter depletion of the finantial capacity of this sector, notably in the late seventies, and the feasibility of the privatisation of the electricity sector.
\end{abstract}

